\title{
SURGICAL TREATMENT OF STRESS URINARY INCONTINENCE: A 3-YEAR FOLLOW-UP.
}

\section{S. Bandiera, G. Giunta, A. Aloisi, M. Arena, I. Iozza, M.G. Matarazzo, R. Morello, G. raciti, F. Rapisarda, S.G. Vitale, A. Cianci}

Department of Gynaecology and Microbiology, S. Bambino Hospital, Catania University, Catania, Italy

Key words

SUI, Transobturator tape, obturator foramen, erosion, polypropylene tape, QoL.

\section{SUMMARY}

OBJECTIVES: To evaluate the objective and subjective midterm outcomes of transobturator tape (TOT) in the treatment of female stress urinary incontinence (SUI).

MATERIALS AND METHODS: A total of 114 consecutive patients affected by

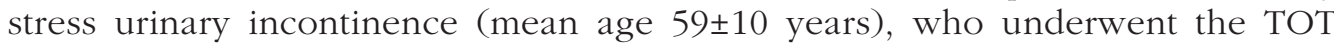
procedure between July 2004 and May 2008 (46 patients received the Safyre, 30 patients the PelviLace, 20 patients the Monarc, 10 patients the DynaMesh and 8 the Align sling), were assessed in June 2008. An evaluation of the patients, based on history, physical examination, stress test, urodynamic tests, and the compilation of two specific quality of life questionnaires, was performed before and after surgery.

RESULTS: The therapeutic midterm failure rate for the TOT procedure was $4.4 \%$ ( 5 of 114 patients). The midterm cure rate was 95.6\% (109 of 114 patients), 7 (6.1\%) of those patients only improved, still with minimal residual urinary leakage. Clinical signs for bowel, urethral, or bladder injuries were undetectable. Intraoperative bleeding, postoperative field infections, or postoperative pelvic floor relaxations were not noted. Three patients (2.6\%) presented a little small area of mesh erosion within 6 months from surgery. We also noticed a few obstructive symptoms and irritative symptoms: 4 of $114(3 ., 5 \%)$ patients showed urge de novo urge symptoms. A high grade degree of satisfaction was assessed reported by QoL questionnaires ( $\mathrm{p}<0.001)$.

CONCLUSIONS : The midterm results of this study show that the TOT procedure is a simple, safe, and effective technique in thefor treatingment of female stress urinary incontinence. 


\section{INTRODUCTION}

Stress urinary incontinence (SUI) is defined by the International Continence Society (ICS) as "an involuntary leakage of urine on effort or exertion, sneezing or coughing"[1], happening without the detrusor muscle being contracted when pressure inside the urinary bladder exceeds a maximum closing pressure of the urethra ${ }^{[2]}$. SUI is mainly caused by injury to the supporting structures of the urethra, which then does not respond properly to increased abdominal pressure.

Thise condition has a serious impact on the quality of life, impairing professional and sexual activity, and it affects a significant number of women in the world. The reported prevalence of SUI is variable in different studies, but is strictly linked with age as well as with the number of vaginal births[3, 4].

Until the mid-1990s the gold standard forto treating SUI surgically was Burch colposuspension but a few years ago Ulmsted and Petros ${ }^{[5]}$ described a new concept of mid-urethral support that drastically changed the surgical approach: the tensionfree vaginal tape (TVT) -the procedure of urethral suspension via the retropubic access. Several large, randomiszed clinical trials have demonstrated stress incontinence cure rates of more thanover $80 \%$ after more than 5 years follow-up[6; 7]. Various complications have nonetheless been reported, some minor such as bladder perforations, others potentially serious such as vascular or bowel injuries[6; 7].
In 2001 Delorme[8] described a new surgical approach using the transobturator tape (TOT), with the aim of maintaining the same position, under the mid urethra, and the same efficacy as TVT, while reducing or even eliminating the complications related to penetration of the retropubic space. The original aspect of this new TOT technique, is the placement of the tape through a safety zone in both the obturator foramens, creating a hammock that should is to support the urethra, instead of urethral suspension, as occurs with the TVT.

\section{MATERIALS AND METHODS}

The aim of this study was to evaluate the objective and subjective midterm outcomes (mean follow-up $29 \pm 10$ months, range 2-46) of transobturator tape (TOT) in the treatment of female stress urinary incontinence (SUI).

\section{TOT Technique}

The technique used was the first described by Delorme[8].

All patients are given administered $1 \mathrm{~g}$ of Ceftriaxone or $500 \mathrm{mg}$ of Levofloxacin intravenously at time of anaesthesia, and are subjected to an iodine antiseptic prophylactic vaginal wash before commencement ofstarting the operation. The mode type of anaesthesia depends on the patient's request, but we usually practice a spinal anaesthesia or a deep sedation by with Propofol. A 16 Ch Foley catheter is put into placed for the op- 
eration, and is then removed on the first postoperative morning. No diagnostic cystoscopy is performed during or after surgery. A $15-\mathrm{mm}$ anterior colpotomy, is made vertically $1 \mathrm{~cm}$ below the external urethral meatus. Dissection of the paraurethral spaces is then made laterally toward the ischiopubic ramus. The external needle entry point is made in the genitofemoral fold by with a cutaneous incision made slightly above a horizontal line passing through the clitoris. The device's needle of the device is introduced through this orifice, it crosses the obturator membrane in the safety zone, and goes through the paraurethral space until it is exteriorizsed by the vaginal incision. The same procedure is performed on the opposite side, and then the tape is then adjusted in a tension-free manner adjustment is made to the tape.

The procedure ends with theby cutting of the exceeding tape and with the suture of the anterior colpotomy. Patients are discharged when the post-void residual urine volume is less than $50 \mathrm{ml}$, usually the day after surgery.

\section{Preoperative evaluation}

In June 2008, we retrospectively assessed 114 consecutive female patients, mean age $59 \pm 10$ years (range

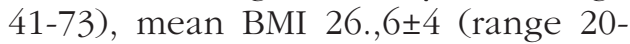
41), who had undergone a TOT implantation for SUI from between July 2004 toand Mmay 2008.

The different kits were used as follows:

- 46 TOT Safyre (Promedon, Cordoba, Argentina);
- 30 TOT PelviLace (Bard, Covington, GA);

- 20 TOT Monarc (AMS, Breukelen, The Netherlands);

- 10 TOT Dynamesh (SIS, Aachen, Germany);

- 8 TOT Alygn (Bard, Covington, GA).

Before surgery, the patients' evaluation included their history, a physical examination, cough stress test, urodynamic tests and routine laboratory tests.

$73 ., 5 \%$ (84 of 114) of patients was affected by genuine stress urinary incontinence, the remaining $26 ., 5 \%$ $(n=30)$ of patients had mixed urinary incontinence. This group of patients was treated with antimuscarinic drugs for some months before surgery and it was classified as the "pre-existent urge group".

Of the 114 patients, 33 had undergone surgery to repair pelvic organ prolapse (different kinds and degrees) using the vaginal approach.

The King's Health Questionnaire and the PISQ-12, were administrated to patients to evaluate their QoL.

\section{Postoperative evaluation}

The total ofAll 114 consecutive patients, who underwent the TOT procedure from July 2004 to May 2008, were asked to undergo a periodical follow-up: the postoperative followup included an initial visit medical examination 15 days after surgery. Additional visits medical examinations were scheduled at 1, 6, and 12 months, and then every year.

During the visitsmedical examination, the patients underwent history 
and a physical examination to evaluate the presence of mesh erosion. Continence was evaluated by with the cough stress test.

By At the end of the visit each patient answered the same self-assessment quality -of- life questionnaire that they had answered before surgery.

\section{RESULTS}

The Ffollow-up for this study has been closedended on June 2008, thus ranging from 2 to 46 months. The median follow up time was $29 \pm 10$ months. The mean operative time was 25.,6 minutes (range 20-38 minutes). There were no deaths and, no major complications, notably no injury of major vessels, neurological or gastrointestinal complications.

Up to the $6^{\text {th }}$ month of follow-up, only 3 patients $(2, .6 \%)$ showed a significant degree of mesh erosion degree. Such These patients underwent the surgical removal of the exceeding mesh. Only a topic oestrogen therapy was necessary, in case of a little small area of mesh erosion. No erosions were was found after the $6^{\text {th }}$ month follow-up.

In 4 of 114 patients $(3 ., 5 \%)$ we noticed the occurrence of de novo urge.

We used the cough stress-test to evaluate the continence: $89 ., 5 \%$ of patients $(n=102)$ were negative to the cough stress test and we called those "cured group"; 6.,1\% (n=7) of patients had only a minimal residual urinary leakage, this was the "improvedment group"; the last $4 ., 4 \%(n=5)$ of pa- tients were positives to the cough stress test, the "failedure group". So the success rate was $95 ., 6 \%$.

The 5 patients of the failedure group had been operated with the TOT Pelvilace Kit reabssorbable acellular porcine collagen mesh: 2 were reoperated with TOT Dynamesh, 3 with TOT Safyre and they did no't show any erosions, presence of urge de novo urge, and were negative to the stress test up to the 6th month of the follow up. Through the comparison of the questionnaires filled up out by the patients before and after surgery, we could detect a substantial improvement of their quality of life: in particular an improvement of health (KHQ) and of sexual functions (PISQ-12).

\section{DISCUSSION}

The goal of SUI surgery is to restore a perfect urinary continence with minimal complications.

The pathophysiological concept described, first by Petros[9], then by De Lancey[10], of a backboard urethral support, a flat layer situated between the mid-third and the distal-third of the urethra, onto which the urethra is compressed and therefore closed, seems to be one of the mechanisms responsible for continence. The TVT and TOT methods make it possible to reconstruct this backboard urethral support and then its suburethral resistance. In particular in the TOT technique the path of the tape, crossing the obturator foramen, muscle and fascia, reproduces the natural suburethral suspension by reinforcing the 
urethropelvic ligaments, and restores continence. At the end the retropubic space is spared, while in the TVT it was used for the passage of the tape.

In fact, although over the last few years, (TVT) has become the most common form of surgery for treating female urinary incontinence, because it is effective and easy to perform, the retropubic placement of the TVT has been associated with a number of perioperative and postoperative complications, including dysuria, urinary retention, and de novo symptoms, as well as bladder, bowel, and vascular injuries. [6; 7; 11]. Most complications appear to be related to the blind upward vaginal passage of the trocars in the retropubic space. In order to avoid these problems, Delorme suggested using the obturator foramens, rather than the retropubic space, as a route for the Prolene tape. Intra-operative bleeding, post-operative field infection and voiding difficulties are less frequent with the TOT, even though this result might be partially due to the relatively short follow-up period for the TOT procedure, as well as to the relatively small study sample size. Nevertheless, the TOT is easier and simpler for both surgeons and patients, as it does not require urethral catheteriszation or diagnostic cystoscopy during surgery.

The most serious risk seemed to be neurological, but the anatomical studies carried out by Delmas showed that, using the trans-obturator route in the out-in procedure, there is a minimum of $3 \mathrm{~cm}$ safety zone from the nearest hazardous structures (obturator bundle)[12].
In our experience involving 114 patients no perioperative complications were found and no patients presented neurological complications, or persistent pain.

Only four patients (3.,5\%) reported an onset of de novo unstable bladder due to an urethral stenosis treated by dilatation.

Three patients had a tape erosion within the $6^{\text {th }}$ month. An important vaginal discharge without any other symptoms, was the only reported complaint in one out of the three cases. The examination showed a vaginal defect of 2-6 $\mathrm{mm}$. The exceeding area of the tape has been was resected and the healing per secundam was complete after two weeks. All three patients remained continent.

In allAltogether, $30(26, .3 \%) \mathrm{pa}-$ tients reported symptoms of bladder overactivity before surgery, 24 (21\%) of them continued having the same problem postoperatively. This improvement might be explained by pelvic floor damage repair.

We In order to assessed the success of this procedure both objectively and subjectively. So we used two QoL questionnaires to evaluate the subjective satisfaction and the cough stress test to determinate the rate of success of the technique.

In our series of 114 cases, the TOT technique gave provided the same levels of success levels as the previously used TVT technique [13-15] and better results than those obtained for Burch colposuspension. We are aware that the follow-up is still too short, but the results do not seem to deteriorate with time. 


\section{CONCLUSIONS}

The midterm results of this study show that the TOT procedure is a simple, safe, and effective technique for the treatment of female stress urinary incontinence, with maintenance, after a 3-year minimum follow-up, of high cure rates comparing favourably with those reported for TVT.
For correspondence:

GiunTa Giuliana

Via I Risorgimento, 32

98020 Pagliara (ME) - Italy

e-mail: giulygiu1983@hotmail.it

\section{REFERENCES}

1 - ABRAMS P., CARDOZO L., FALL M., GRIFFITHS D., ROSIER P., ULMSTEN U., VAN KERREBROECK P., VICTOR A., WEIN A. :

The standardization of terminology of lower urinary tract function: report from the standardisation subcommittee of the international continence society.

Neurourol Urodynam 2002; 21: 167-78

2 - ENHORNING G. :

Simultaneous recording of the intravesical and intraurethral pressure.

Acta Obstet Gynecol Scand 1961;276 s:1 - 69. 4.

3 - MINASSIAN V.A., DRUTZ H.P., AL-BADR A. :

Urinary incontinence as a worldwide problem.

International Journal of Gynecology and Obstetrics 82 (2003) 327-338.

4 - HANNESTAD Y.S. et al. :

A community-based epidemiological survey of female urinary incontinence:

The Norwegian EPINCONT Study.

J clin Epidemiol. 2000; 53(11) :1150-1157.

5 - ULMSTEN U., PETROS P. :

Intravaginal slingplasty (IVS): an ambulatory surgical procedure for treatment of female urinary incontinence.

Scand J Urol Nephrol 1995; 29(1): 75-82.

6 - EL-BARKY E., EL-SHAZLY A., EL-WAHAB O.A. et al. :

Tension free vaginal tape versus Burch colposuspension for treatment of female stress urinary incontinence.

Int Urol Nephrol. 2005; 37:277-281. 
7 - SANJURJO S., BEN YOUNES A., BONNET P., ANDRIANNE R., DE LEVAL J. : Le TVT: Traitement révolutionnaire de l'incontinence urinaire.

Rev Med Liege 2002; 57:765-70.

8 - DELORME E. :

Transobturator urethral suspension: mini-invasive procedure in the treatment of stress urinary incontinence in women.

Prog Urol 2001; 11(6):1306-13.

9 - PETROS P., ULMSTEN U. :

An integral theory on female urinary incontinence. Experimental and clinical considerations.

Acta Obstet Gynecol Scand 1990; (Suppl. 69):153.

10 - DE LANCEY J.O.L. :

Structural support of the urethra as it relates to stress urinary incontinence.

The hammock bypothesis.

Am J Obstet Gynecol 1994; 170:1713-23.

11 - NILSSON C.G., FALCONER C., REZAPOUR M. :

Seven year follow up of the tension-free vaginal tape procedure for treatment of urinary incontinence.

Obstet Gynecol 104: 1259-1262, 2004.

12 - DELMAS V., HERMIEU J.F., DOMPEYRE P. et al. :

E'le éments anatomiques concerne s par la bandelette trans-obturatrice

(URATAPE) dans le traitement de l'incontinence urinaire chez la femme.

Prog Urol 2001; 11 (Suppl. 1):5.

13 - LIAPIS A., BAKAS P., GINER M. et al. :

Tension-free vaginal tape versus tension-free vaginal tape obturator in women with stress urinary incontinence.

Gynecol Obstet Invest. 2006;62:160-164.

14 - LATTHE P.M., FOON R., TOOZS-HOBSON P. :

Transobturator and retropubic tape procedures in stress urinary incontinence: a systematic review and meta-analysis of effectiveness and complications.

BJOG. 2007; 114:522-531.

15 - SUNG V.W., SCHLEINITZ M.D., RARDIN C.R. et al. :

Comparison of retropubic versus transobturator approach to midurethral slings: a systematic review and metaanalysis.

Am J Obstet Gynecol. 2007; 197:3-11. 